\title{
The Efficacy of Percutaneous Steroid Injection via Cricothyroid Membrane for Reinke's Edema
}

\author{
Woojoo Nam (D), Sun Woo Kim Di , Sung Min Jin D, and Sang Hyuk Lee (D) \\ Department of Otorhinolaryngology-Head and Neck Surgery, Kangbuk Samsung Hospital, Sungkyunkwan University School of Medicine, \\ Seoul, Korea \\ 라인케씨 부종 환자에서 경윤상 갑상막 접근을 통한 성대 내 스테로이드 주입술의 효용 \\ 남우주, 김선우, 진성민, 이상혁 \\ 성균관대학교 의과대학 강북삼성병원 이비인후과학교실
}

Background and Objectives Reinke's edema is a benign vocal fold disease caused by an edematous laryngeal superficial layer of lamina propria. The first line treatment is cessation of smoking and laryngeal microsurgery. The aim of the study is to evaluate the feasibility and efficacy of percutaneous steroid injection via cricothyroid membrane in patients with Reinke's edema.

Materials and Method From Jan 2010 to July 2018, 33 Patients with Reinke's edema managed by vocal fold steroid injection via the cricothyroid membrane were included in this study. We compared medical records of laryngoscopy, stroboscopy and Multi-Dimensional Voice Program analysis at pre-treatment and post-treatment. Subjective voice improvement was evaluated using Voice Handicap Index-30 (VHI-30).

Results $75.7 \%$ of the patients showed partial response and $6.06 \%$ showed complete response. $93.94 \%$ were present smokers and only 4 patients ceased smoking after the treatment. In acoustic analysis, the pre-treatment mean value of jitter, shimmer, and noise to harmonic ratio was $2.30 \pm 3.21,9.34 \pm 10.37,1.11 \pm 2.90$ each. The post-treatment value was $2.20 \pm 1.89,6.96 \pm 5.30$, $0.20 \pm 0.09$ respectively and none of the parameters were statistically significant. For subjective symptom improvement, 25 (75.8\%) patients showed a better score on post-treatment VHI-30 compared to pre-treatment.

Conclusion According to our study, steroid injection is a relatively safe and effective procedure for patients with Reinke's edema. A vocal fold steroid injection via the cricothyroid membrane can be an alternative treatment option for those who are not able to undergo conventional laryngeal microscopic surgery, however cessation of smoking is necessary for effective treatment.

Keywords Vocal cords; Reinke's edema; Percutaneous; Steroid injection; Treatment.

\section{서 론}

라인케씨 부종은 성대의 상피하층 라인케씨 공간에 있는 결합조직의 만성적인 부종으 로 인해 발생하는 질환이다. 성대부종의 정도에 따라서 다양한 임상 양상을 보이며 이 는 점막 병변의 질량과 크기, 긴장도에 의해 결정된다. ${ }^{1)}$ 성대점막의 긴장도가 감소하고 점막의 부종으로 인한 부피의 증가로 성대진동이 감소하여 저음이 현저한 발성을 하게

\begin{abstract}
Received October 13, 2019
Revised November 21, 2019

Accepted December 6, 2019
\end{abstract}

\section{Corresponding Author}

Sang Hyuk Lee, MD

Department of Otorhinolaryngology-

Head and Neck Surgery,

Kangbuk Samsung Hospital,

Sungkyunkwan University

School of Medicine,

29 Saemunan-ro, Jongno-gu,

Seoul 03181, Korea

Tel $+82-2-2001-2269$

Fax $+82-2-2001-2412$

E-mail entlsh@hanmail.net

\section{ORCID iDs}

Woojoo Nam (ID

https://orcid.org/0000-0002-5070-6939

Sun Woo Kim (D)

https://orcid.org/0000-0002-2894-1334

Sung Min Jin (D)

https://orcid.org/0000-0003-0714-5862

Sang Hyuk Lee (D)

https://orcid.org/0000-0003-4412-3486

\author{
This is an Open Access article distributed \\ under the terms of the Creative \\ Commons Attribution Non-Commercial \\ License (https://creativecommons.org/ \\ licenses/by-nc/4.0) which permits \\ unrestricted non-commercial use, \\ distribution, and reproduction in any \\ medium, provided the original work is \\ properly cited.
}


된다. ${ }^{2}$ 주요 원인은 흡연으로 알려져 있으나 최근에는 음성 남 용과 인후두 역류 질환도 위험 요인으로 보고되고 있다. ${ }^{3)}$ 일 차적 치료는 금연 및 음성 치료를 시행하여 볼 수 있으나 증 상의 호전이 없거나 심한 경우에는 전신마취하 후두 미세수 술을 시행한다. ${ }^{4}$

스테로이드는 주로 항부종 및 항염증 효과가 있으며 이비 인후과 영역에서는 비강 용종, 인후두의 부종, 구강 궤양 및 돌 발성 난청에서 쓰이고 있다. ${ }^{5)}$ 비강 용종을 동반한 만성 부비동 염 환자에서 내시경하 부비동 수술 후 비강 내 스테로이드 주 입술을 시행 시 재발률을 낮춘다는 연구도 있다. ${ }^{6)}$ 단기적 소 량의 스테로이드 경구 복용은 중대한 전신적 부작용을 비교적 일으키지 않으나 양성 성대 질환의 경우 장기간의 복용이 필 요하며 경구 복용을 통해서는 라인케씨 공간에서 스테로이드 를 높은 농도로 유지할 수 없어 비효율적이다. ${ }^{7)}$ 최근 스테로이 드 성대 내 국소 주입술이 성대결절에 좋은 효과를 보이는 것 으로 보고되고 있으며, 일부 성대 용종과 라인케씨 부종 환자 에서도 좋은 효과가 있다는 보고가 있다. ${ }^{48}$

성대 내 스테로이드 주입술은 국소마취하에 후두 내시경과 주사기를 이용하여 성대의 라인케씨 공간에 스테로이드를 주 입하는 시술로서 경구 복용과는 다르게 국소적으로 높은 농 도를 유지하며 약물을 주입할 수 있어 효과적이다. 또한 전신 마취를 요하지 않고 처치실에서 경구강 혹은 경피적으로 시 행할 수 있는데 경구강으로 시행 시 구역반사가 발생할 수 있 고 성대의 고유층을 관통하여 주사를 하기 때문에 반흔이 생 길 수 있다. 반면 경피적 접근법은 구역반사를 유발하지 않고 성대의 점막을 보존하면서 시술할 수 있는 장점이 있다. ${ }^{9}$ 본 연구에서는 라인케씨 부종 환자에서 성대 내 스테로이드 주입 술의 성대 부종의 개선 정도와 환자의 음향학적 수치 및 증상 의 호전 여부를 알아보고자 하였다.

\section{대상 및 방법}

2010년 1월 2018년 7월까지 본원 이비인후과 외래를 내원 하여 라인케씨 부종으로 경윤상 갑상막 접근을 통한 성대 내 스테로이드 주입술을 시행받은 환자의 의무기록 및 영상 소견 을 바탕으로 후향적 연구를 시행하였다(No. KBSMC 2019-11038). $70^{\circ}$ rigid telescope 이용한 후두 스트로보스코피 검사 나 일반 후두 내시경을 통하여 라인케씨 부종을 진단하였다.

성대 내 스테로이드 주입술은 환자의 비강 및 비인두의 마 취를 위해 4\% lidocaine과 1:2000 epinephrine이 적셔진 pledget 거즈를 일측 비강 내에 세 장씩 패킹하고 윤상갑상막 부위 의 피부의 마취를 위해 2\% lidocaine과 1:100000 epinephrine이 포함된 주사액을 치과용 주사기를 이용하여 주입하였
다. 다음으로 구역반사를 방지하기 위해 $10 \%$ lidocaine hydrochloride를 이용하여 구인두에 1 회씩 분무하였다. 보조자 는 굴곡형 후두경을 이용하여 시술자에게 성대를 보여주고 시술자는 환자의 전면에서 triamcinolone acetonide suspen$\operatorname{sion}(40 \mathrm{mg} / \mathrm{mL})$ 을 $26 \mathrm{G}$ 바늘을 이용하여 윤상갑상막을 통 과하여 성대의 고유층의 천층에 주입하였다. 환자는 시술 후 24시간 동안 음성 안정을 취하도록 교육하였다.

성대 내 스테로이드 주입술의 치료 효과를 평가하기 위하여 2 명의 전문의가 치료 전과 후의 스트로보스코피 또는 내시경 소견을 이용하여 비교하였다. 시술 전 후두 영상과 시술 약 4 8주 후의 정지 영상을 비교하여, 라인케씨 부종이 완전히 없어 진 경우는 완전 반응, $50 \%$ 이상 면적이 감소한 경우는 일부 반 응, 그 외의 경우는 무반응의 3 군으로 분류하여 분석하였다.

음향학적 분석은 Multi-Dimensional Voice Program(Model 4500; Kay Elemetrics Corp., Lincoln Park, NJ, USA)을 이 용하였다. 마이크에서 $10 \mathrm{~cm}$ 떨어진 거리에서 가장 편안한 높 이와 크기의 목소리로 2 3초간 '아(/a/)'의 발성을 3회 반복하 도록 하였다. 발성된 음성은 $25 \mathrm{kHz}$ 의 sampling rate로 채취 하였고 3 회 측정한 음성 표본 중에서 가장 안정된 것을 골라 연속된 3초 구간을 분석하였다. 음향 변수로는 jitter, shimmer, noise to harmonic ratio(NHR)를 선택하였다. 공기역학 적 검사에서는 Aerophone II(Voice function analyzer, Kay Elemetric Corp.)를 이용하여 기본 단모음 '아(/a/)'를 발성하 도록 하여 가장 안정되고 편안하게 발성된 소리를 선택한 후 최장 발성 지속시간(maximum phonation time)을 3회 측정 하였고 이 중 최대치를 사용하였다. 시술 전 시행한 음향학적 분석과 시술 4 8주 후의 검사 결과를 비교하였다.

주관적인 증상의 호전 정도는 한국어판 음성장애지수-30 (Voice Handicap Index, VHI)을 이용하여 시술 전과 시술 4 8 주 후의 점수를 비교하여 분석하였다. 설문은 emotional, functional, physical 세 가지 분류에서 각 10가지 세부항목 으로 구성되어 있고, 각 항목의 점수를 0 4점까지 환자가 답 을 한 후 합산하여 산출하였다.

수집된 자료는 통계 분석 프로그램 Statistics Package for the Social Sciences(SPSS, version 15.0, SPSS Inc., Chicago, $\mathrm{IL}, \mathrm{USA}$ )로 분석하였다. 각각의 항목에 대하여 시술 전후의 비교는 Paired Student t-test를 실시하였고, 통계 검정상 $\mathrm{p}<$ 0.05 를 유의한 것으로 간주하였다.

\section{결 과}

총 33명의 라인케씨 부종 환자 중에서 남성이 19명, 여성이 14명으로 연령은 47 75세까지 분포하였으며 평균 연령은 
56.24세였다. 27명에서 양측으로 관찰되었으며 좌측과 우측 이 각각 3명씩 분포하였다. 환자의 직업은 여행가이드, 택시기 사, 식당보조, 보험판매원 등 음성 남용이 있는 환자는 5 명으 로 나머지 대부분의 환자들은 평상시 음성 남용을 보이지는 않았다. 성대 내 스테로이드 주입술은 모든 환자에서 1회만 시 행되었고, 1회 스테로이드 주입량은 0.1 0.4 cc로 평균 0.197 $\mathrm{cc}$ 이다. 전체 대상 환자 중 31 명이 흡연 중이었으며 평균 흡연 기간은 21.96갑년이었다(Table 1).

성대 내 스테로이드 주입술 후 시행한 형태학적 분석에서는 총 33 명의 환자 중 2 명에서 완전 반응을 보였으며 25 명에서는 부분적 반응, 6 명에서는 시술 전과 비교하여 차이를 보이지 않 았다. 부분적 반응을 보인 25명의 환자 중 23명(92\%)이 흡연 중이었고, 이 중 4명(16\%)이 시술 후 금연을 시작하였다. 또한, 이 중 3명(12\%)의 환자는 스테로이드 주입 후 성대 부종이 시 술 후 2 3달 사이에 재발하였다(Figs. 1, 2, and 3)

음향학적 분석에서 시술 전 jitter, shimmer, NHR 값은 각 각 $2.30 \pm 3.21,9.34 \pm 10.37,1.11 \pm 2.90$ 이었으며 시술 후는 각 각 $2.20 \pm 1.89,6.96 \pm 5.30,0.20 \pm 0.09$ 이었다. 시술 전후의 각 항목의 평균값의 차이는 $0.10 \pm 1.98,2.37 \pm 9.53,0.91 \pm 2.88$ 으

Table 1. Demographic features of Reinke's edema patients

$\begin{array}{lc} & \text { Value } \\ \text { Total } & 33 \\ \text { Age (yr) } & 56.24 \pm 8.76 \\ \text { Sex (M:F) } & 19: 14 \\ \text { Side (both:left:right) } & 27: 3: 3 \\ \text { Injected volume mean value (cc) } & 0.197 \pm 0.083 \\ \text { Smoker } & 31(93.93) \\ \text { Pack-year } & 21.96 \pm 16.09\end{array}$

Variables are presented as mean \pm standard deviation or number (percentage)

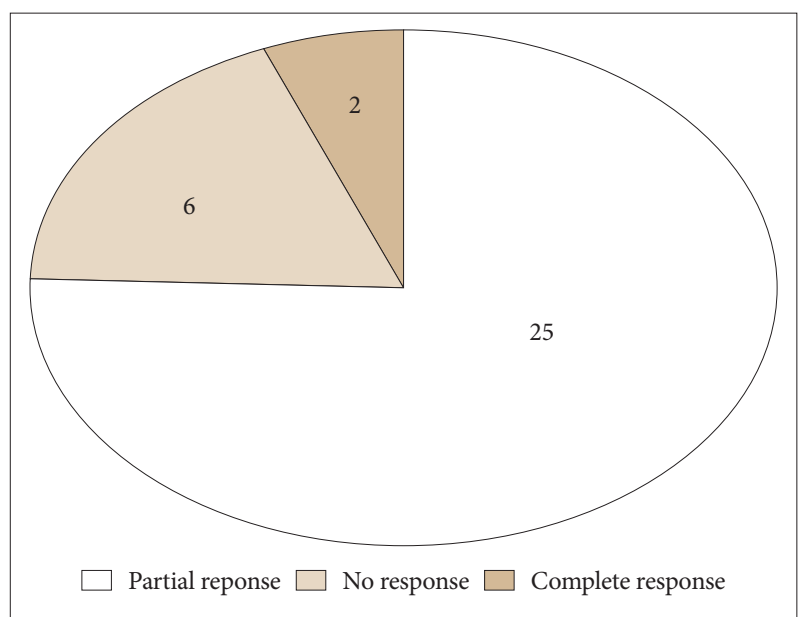

Fig. 1. Morphological evaluation of Reinke's edema patients comparing pre-treatment and post-treatment.
로 관찰되었으며 시술 전에 비하여 수치상으로는 호전을 보였 으나 통계학적으로 유의한 항목은 관찰되지 않았다. 최장 발 성 지속시간도 $13.94 \pm 2.24$ 에서 $16.94 \pm 2.43$ 으로 호전을 보였 으나 통계적으로는 유의하지 않았다(Table 2). 주관적인 호전 여부 판단을 위한 VHI-30 설문에서는 $75.8 \%$ 의 환자에서 시 술 전과 비교하여 호전을 보였으며 시술 전과 비교하여 $\mathrm{emo}^{-}$ tional, functional, physical 항목 모두 유의한 차이를 보이지 않았다(Table 3). 시술 후 경과 관찰 기간 동안 성대위축, 출 혈, 약물 침착으로 인한 백반증 등 부작용은 없었다.

\section{고 찰}

라인케씨 부종은 후두 천층의 고유층 혹은 라인케씨 공간 의 상피하조직의 부종으로 발생한다. 라인케씨 부종의 조직학 적 특성으로는 상피층은 얇고 그 기저막 밑으로 섬유탄력소 가 적재되어 있고 상피하층으로는 다수의 확장된 모세혈관과 내피층의 부종이 관찰된다. 전자현미경에서는 상피하조직에서 상피로 삼출액이 유출되어 세포 내 공간이 확장되어 있다. ${ }^{10)}$ 라인케씨 부종의 후두 미세수술에서는 성대점막의 천층을 절개하고 부종이 있는 조직을 제거하고 과도한 점막은 절제 후 다시 경계를 맞추어 덮어두는 방법으로 이용된다. ${ }^{11)}$ 수술 의 결과에는 금연 여부가 재발의 가능성을 낮추고 추가로 음 성 변화나 인후두 염증의 호전에도 많은 영향을 미친다. ${ }^{12}$ 흡 연 이외에도 인후두 역류가 성대점막의 취약성 증가 및 부종 을 유발하여 라인케씨 부종 환자의 3.2 13\% 정도의 원인으 로 알려져 있다. ${ }^{3,13,14}$

라인케씨 부종은 흡연자에서 주로 발생하여 흡연 기간이 길 어질수록 증상도 심해진다고 알려져 있다. 흡연은 후두 악성 종양의 위험인자로 라인케씨 부종 환자에서 상당수가 흡연자 이기 때문에 내시경에서의 저명한 부종 양상에도 불구하고 드물지만 악성 종양으로 진단되는 경우도 보고되었다. ${ }^{13,15)}$ 조직 학적 분석에서는 흡연 기간과 흡연량에 비례하여 병변이 더 악화되며 이 중 전체적인 흡연 기간이 부종에 영향을 크게 미 친다. ${ }^{3} 120$ 명의 환자를 대상으로 후두 미세수술 시 시행한 조 직병리 결과에서도 30 명의 환자에서 경도의 이형성증이 보고 되었다. 라인케씨 부종은 주로 흡연에 의해서 유발되고 흡연 은 후두 악성 종양의 위험요인이기 때문에 양성 성대 질환과 달리 조직병리 검사의 필요성이 있다. ${ }^{10)}$

42 명을 대상으로 경구강 접근을 통한 성대 내 스테로이드 주입술을 시행한 다른 연구에서는 33\%에서 완전 소실, $64 \%$ 에서 부분적 소실, $3 \%$ 에서는 호전을 보이지 않았다. 33 명을 대 상으로 경피적 접근을 통한 또 다른 연구에서는 $43.3 \%$ 에서 완 전 소실, $30 \%$ 에서 부분적 소실을 보였다. ${ }^{8)}$ 본 연구에서는 완 


\section{JKSLP}

전 소실된 환자는 2 명으로 부분적 소실은 $75.7 \%$ 에서 관찰되 었으며 주관적인 증상 호전은 $75.8 \%$ 에서 확인되었는데 이는 타 연구에 비하여 흡연자의 비율이 굉장히 높았으며 더 장기 간 동안 추적 관찰하지 못한 것이 원인으로 생각된다. 시술 후 에도 증상이 지속된 일부 흡연자에 대해서는 후두 미세수술 을 시행하였다.

음성학적 분석에서는 최장 발성 지속기간이 유의미하게 증 가하였으며 남녀 모두에서 기본 발성 주파수의 상승을 보였
다. ${ }^{4}$ 라인케씨 부종 환자를 대상으로 후두 미세수술을 시행 후 jitter, shimmer, NHR이 모두 감소하였으나 유의하지 않았다 는 연구 결과도 있으며 기본 주파수는 연구자에 따라 증가한 경우도 있었으며 감소된 경우도 있었다. 흡연에 의해 섬유아 세포의 구조적 변화가 발생하면 성대 고유층에 있는 섬유 기 질의 과증식으로 금연을 통한 보존적 치료 혹은 수술적 치 료 후에도 음성의 호전은 부분적으로 있을 수 있으나 완전한 회복은 어렵게 만든다. ${ }^{16)}$
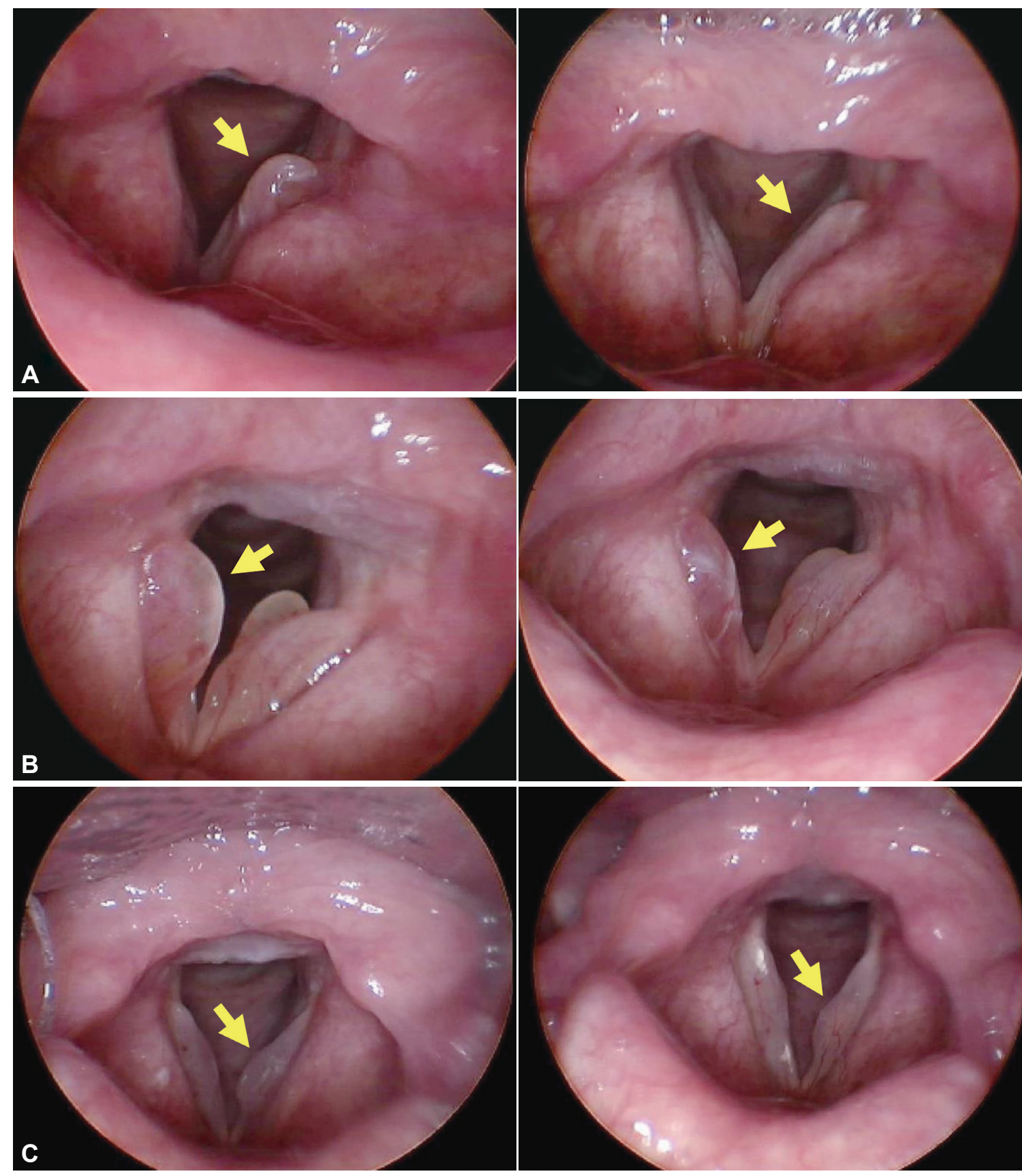

Fig. 2. Morphological analysis of Reinke's edema comparing pre-treatment (left) and post-treatment (right). Complete response (A, arrows). Partial response (B, arrows). No response ( $\mathrm{C}$, arrows). 

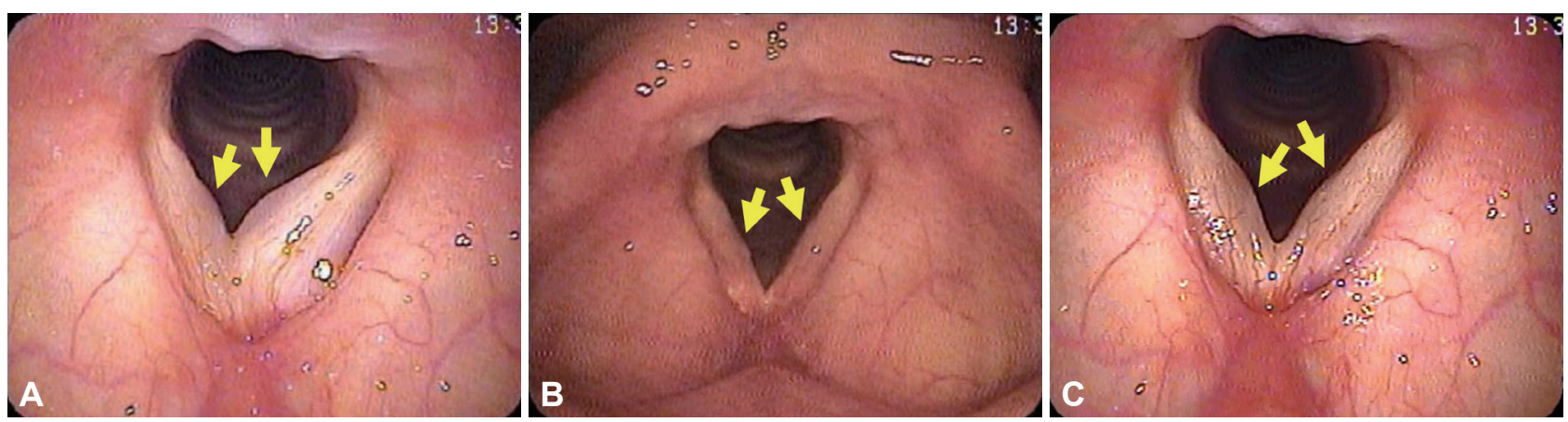

Fig. 3. Recurred cases after steroid injection. Pre-treatment (A, arrows). Complete response of edematous lesion a month after treatment ( $B$, arrows). Two months after treatment with mild edema ( $C$, arrows).

Table 2. The difference between pre-treatment and post-treatment in acoustic analysis

\begin{tabular}{lcrcc} 
& Pre-treatment & Post-treatment & Difference & $\begin{array}{c}\text { p- } \\
\text { value }\end{array}$ \\
Jitter & $2.30 \pm 3.21$ & $2.20 \pm 1.89$ & $0.10 \pm 1.98$ & 0.87 \\
Shimmer & $9.34 \pm 10.37$ & $6.96 \pm 5.30$ & $2.37 \pm 9.53$ & 0.45 \\
NHR & $1.11 \pm 2.90$ & $0.20 \pm 0.09$ & $0.91 \pm 2.88$ & 0.34 \\
MPT & $13.94 \pm 2.24$ & $16.94 \pm 2.43$ & $3.01 \pm 2.12$ & 0.41 \\
\hline
\end{tabular}

Variables are presented as mean \pm standard deviation. NHR: noise to harmonic ratio, MPT: maximum phonation time

Table 3. Subjective symptom improvement (Voice Handicap Index30) comparing pre-treatment and post-treatment

\begin{tabular}{lccc} 
& Pre-treatment & Post-treatment & p-value \\
Emotional & $20.19 \pm 6.72$ & $15.41 \pm 5.16$ & 0.124 \\
Functional & $18.32 \pm 7.24$ & $12.11 \pm 6.21$ & 0.235 \\
Physical & $21.17 \pm 6.03$ & $17.28 \pm 5.02$ & 0.458 \\
Total & $59.68 \pm 10.25$ & $44.8 \pm 7.56$ & 0.103 \\
\hline
\end{tabular}

Variables are presented as mean \pm standard deviation

성대 내 스테로이드 주입술은 사회경제적 비용이 적으며 불 필요한 성대의 반흔 형성이 없다는 것이 후두 미세수술과 비 교하여 장점이라고 할 수 있다. 또한 비슷한 성대 내 주입술이 라고 하더라도 경구강 성대 내 주입술의 경우 구역반사가 심 한 경우에는 시행이 어려우며 성대 내부가 아닌 외부에서 주 입하기 때문에 후두 미세수술과 비슷하게 반흔 형성의 가능 성이 있는 단점이 있다. ${ }^{7)}$

시술에 쓰이는 약물로는 주로 dexamethasone과 triamcinolone acetonide가 쓰이는데 두 가지 모두 합성 코르티코 스테로이드의 한 종류이다. 두 약제 모두 내인성 하이드로코 르티손보다는 약리적 효능이 좋지만 triamcinolone acetonide가 dexamethasone보다는 약리적 효능이 다소 떨어진 다. ${ }^{17)}$ Triamcinolone acetonide는 다른 스테로이드와 비교하 여 혈장과 뇌척수액에서 응집되려는 성질이 더 강하여 체액 강 내의 주사용으로는 적절하지 않다는 의견도 있다. ${ }^{18)}$ 하지 만 성대 내 스테로이드 주입술은 스테로이드를 연조직에 주입
하는 것이며 현재까지 triamcinolone acetonide를 이용한 타 연구에서 성대의 일시적인 색소침착 이외에 보고된 중대한 부작용은 없었으며 색소침착은 대개는 일정 시간 경과 후 소실 되었으며 본 연구에서도 약물로 인한 부작용은 없었다.

\section{결 론}

성대 내 스테로이드 주입술은 라인케씨 부종의 일차 치료로 는 제한점이 있으나 환자의 의학적 혹은 사회경제적 이유로 수술이 어려운 경우나 즉각적인 음성 호전을 필요로 하는 환 자에서 금연과 함께 적절히 시행한다면 효과적인 치료 방법으 로 적용될 수 있다고 사료된다.

중심 단어: 성대, 레인케씨 부종, 경피적, 스테로이드 주입술, 치료.

\section{Acknowledgments,}

None.

Conflicts of Interest

The authors have no financial conflicts of interest.

\section{Authors' Contribution}

Conceptualization: Woojoo Nam, Sung Min Jin, Sang Hyuk Lee. Data curation: Woojoo Nam, Sun Woo Kim. Formal analysis: Woojoo Nam, Sun Woo Kim. Investigation: Sun Woo Kim. Methodology: Woojoo Nam, Sang Hyuk Lee. Project administration: Woojoo Nam. Supervision: Sung Min Jin. Validation: Sung Min Jin, Sang Hyuk Lee. Writing—original draft: Woojoo Nam. Writing—review \& editing: Sun Woo Kim, Sung Min Jin, Sang Hyuk Lee. Approval of final manuscript: all authors.

\section{REFERENCES}

1. Lim JY, Choi JN, Kim KM, Choi HS. Voice analysis of patients with diverse types of Reinke's edema and clinical use of electroglottographic measurements. Acta Otolaryngol 2006;126(1):62-9.

2. Kim KH, Sung MW, Kim DY, Lee DW, Lee SJ, Lee SS, et al. Videostrobokymographic analysis of Reinke's edema. Korean J Otolaryngol-Head Neck Surg 2000;43(11):1232-6.

3. Marcotullio D, Magliulo G, Pezone T. Reinke's edema and risk factors: clinical and histopathologic aspects. Am J Otolaryngol 2002; 
23(2):81-4.

4. Tateya I, Omori K, Kojima H, Hirano S, Kaneko K, Ito J. Steroid injection for Reinke's edema using fiberoptic laryngeal surgery. Acta Otolaryngol 2003;123(3):417-20.

5. Hsu YB, Lan MC, Chang SY. Percutaneous corticosteroid injection for vocal fold polyp. Arch Otolaryngol Head Neck Surg 2009;135(8): 776-80.

6. Becker SS, Rasamny JK, Han JK, Patrie J, Gross CW. Steroid injection for sinonasal polyps: the University of Virginia experience. Am J Rhinol 2007;21(1):64-9.

7. Tateya I. Laryngeal steroid injection. Curr Opin Otolaryngol Head Neck Surg 2009;17(6):424-6.

8. Lee SW, Park KN. Long-term efficacy of percutaneous steroid injection for treating benign vocal fold lesions: a prospective study. Laryngoscope 2016;126(10):2315-9.

9. Rubin JS, Sataloff RT, Korovin GS. Diagnosis and treatment of voice disorders. 4th ed. San Diego, CA: Plural Publishing;2014.

10. Pastuszek P, Krecicki T, Zalesska-Krecicka M, Jeleń M, Rak J, Krajewska B. Histological and electron microscopic investigation of Reinke's edema. Pol J Pathol 2003;54(1):61-4.

11. Sataloff RT, Chowdhury F, Joglekar S, Hawkshaw MJ. 17 Reinke's edema. Atlas of Endoscopic Laryngeal Surgery 2011:91.

12. Højslet PE, Moesgaard-Nielsen V, Karlsmose M. Smoking cessation in chronic Reinke’s oedema. J Laryngol Otol 1990;104(8):626-8.

13. García Alvarez CD, Campos Bañales ME, López Campos D, Rivero J, Pérez Piñero B, López Aguado D. [Polyps, nodules, and Reinke edema. An epidemiological and histopathological study]. Acta Otorrinolaringol Esp 1999;50(6):443-7.

14. Kamargiannis N, Gouveris H, Katsinelos P, Katotomichelakis M, Riga $\mathrm{M}$, Beltsis A, et al. Chronic pharyngitis is associated with severe acidic laryngopharyngeal reflux in patients with Reinke's edema. Ann Otol Rhinol Laryngol 2011;120(11):722-6.

15. Lim S, Sau P, Cooper L, McPhaden A, Mackenzie K. The incidence of premalignant and malignant disease in Reinke's edema. Otolaryngol Head Neck Surg 2014;150(3):434-6.

16. Martins RHG, Tavares ELM, Pessin ABB. Are vocal alterations caused by smoking in Reinke's edema in women entirely reversible after microsurgery and smoking cessation? J Voice 2017;31(3):380. e11-380.e14.

17. Laurence L, John S, Keith P. Goodman \& Gilman's The pharmacological basis of therapeutics. 11th ed. New York, NY: McGraw-Hill Medical;2005. p.671-716.

18. Provenzano DA, Fanciullo G. Cervical transforaminal epidural steroid injections: should we be performing them? Reg Anesth Pain Med 2007;32(2):168. 